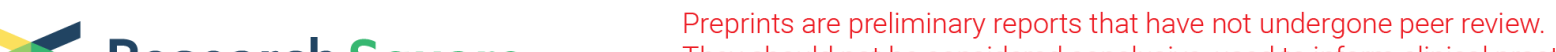 They should not be considered conclusive, used to inform clinical practice, or referenced by the media as validated information.
}

\section{Difficult Tracheal Intubation is More Common among Hazara Tribe and Females in Afghanistan}

\section{Mohammad Sharif Oria}

Kabul University of Medical Sciences

Abdullah Asady

Kabul University of Medical Sciences

Sultan Ahmad Halimi

Kabul University of Medical Sciences

Fahima Negin

Kabul University of Medical Sciences

Jaffer Shah ( $\nabla$ jaffer.shah@drexel.edu )

Drexel University College of Medicine https://orcid.org/0000-0002-8961-218X

\section{Sayed Hamid Mousavi}

Kateb University

\section{Research}

Keywords: Difficult intubation, Intubation difficulty scale, Airway assessment, Predictors, sociodemographic, Intubation

Posted Date: December 31st, 2020

DOI: https://doi.org/10.21203/rs.3.rs-136451/v1

License: (c) (1) This work is licensed under a Creative Commons Attribution 4.0 International License.

Read Full License 


\section{Abstract}

Introduction: Airway management is a considerable challenge for anesthesiologists. The diagnostic value of the screening tests differs in various studies. This is due to the variety in the incidence of intubation, insufficient statistical power, and different test inception. To have a safe intubation, it is essential to perform a precise preoperative airway assessment. However, there is still an argument about which tests and anatomical landmarks would be the best predictors.

Objective: This study is aimed to determine the best predictors and socio-demographic characteristics of difficult intubation among adult patients scheduled for elective surgeries under general anesthesia in Aliabad Teaching Hospital, Kabul, Afghanistan.

Method: A total of 341 patients were selected based on consecutive sampling method. Informed consent forms were obtained before inclusion in the study. Data were collected using a data collection form. Age, gender, ASA physical status and tribe were recorded for each participant. Airway assessment test was conducted before operation for additional consideration. Data were initially entered into an excel data sheet, and then exported to SPSS Statistics version 22 for analysis.

Results: From a total of 341 patients, 193 (56.6\%) were males and 148 (43.4\%) were females. The mean age of the subjects was $36.98 \pm 15.048$ years. More than half $(54.5 \%)$ of the study population were Tajiks. Hazara tribe, female patients, increasing age and systemic disease patients had more difficult intubation. We recognized that, Mallampati classes, mouth opening, thyromental distance, ability to prognath and neck mobility and size were associated with difficult intubation. Multiple logistic regression analysis of the associated factors determined that increase age, ability to prognath and mouth opening were independent predictors of difficult intubation.

Conclusion: Female patients and Hazara tribe were found to have a significant association with difficult intubation on bivariate analysis. Multiple logistic regression analysis determined that increase age, ability to prognath and mouth opening were independent predictors for difficult intubation.

\section{Introduction}

Airway management has been a remarkable contest for anesthesiologists. Endotracheal intubation is one of the recognized life threatening pillars in airway management during induction of general anesthesia while attempting to insert the endotracheal tube with the aid of laryngoscope (Andrade et al., 2018). The diagnostic value of screening tests differs in various studies. This is due to the variety in the incidence of intubation, insufficient statistical power, and different test inception. Differences in patient properties affected by origin may also affect the incidence of difficult intubation (Prakash et al., 2013).

Studies have included variables such as gender, age, tribe classification, ASA physical status classification, Mallampati score (MP), mouth opening (MO), thyromental distance (TMD), ability to 
prognath (AP) and neck mobility and size (NM) in the preoperative airway assessment (Garg and Dua, 2015, Prakash et al., 2013, Wilson and Benumof, 1998).

Risk factors reported to be associated with difficult intubation are mouth opening less than $4 \mathrm{~cm}$, thyromental distance less than $6 \mathrm{~cm}$, Mallampati Class III or higher, neck mobility and size less than $35^{\circ}$ and inability to advance the mandible. Almost all (98\%) difficult intubations may be predicted by performing a thorough and careful assessment of the airways prior to surgery. However, many clinicians pay little consideration to this vital task and bound their investigation of the airway to a superficial examination of the mouth and teeth (Finucane et al., 2003, Combes et al., 2004).

To have a safe intubation, it is essential to perform a precise preoperative airway assessment, but still there is an argument which tests and anatomical landmarks would be the best predictors (Moustafa et al., 2017).

Intubation Difficulty Scale (IDS) score is a function of seven parameters, which result in a progressive and quantitative determination of intubation complexity. This score is calculated by the operator immediately after intubation. IDS score of $=0$ represents easy intubation; IDS score of $=1-5$ represents slight difficult intubation; IDS score of $>5$ represents moderate to major difficult intubation; and IDS score of $=\infty$ denotes impossible intubation (Garg and Dua, 2015). Difficult intubation is defined as more than three attempts (IDS > 5) or more than 10 minutes using direct laryngoscopy to complete tracheal intubation (Prakash et al., 2013, Workeneh et al., 2017).The aim of this study was to find out some best predictors of the preoperative airway assessment and identify socio-demographic characteristics of difficult intubation. This is the first study of its type in Ali Abad Teaching Hospital, Kabul Afghanistan which attempts to provide a base-line data for future researches.

\section{Methods}

This is a cross-sectional study conducted in Aliabad Teaching Hospital (ATH), Kabul University of Medical Sciences, from October 2018 to January 2019. Patients who were scheduled for elective surgery under general anesthesia at Neurosurgery, Orthopedics, Urology and General surgery wards of ATH were chosen to participate in the study. A verbal briefing was provided to introduce the objectives and methodology of the study. Once the participants agreed to take part in the study, they were asked to sign the informed consent form. The sample size estimation was based on the consecutive sampling a common practice is to select all cases which are available in a given period of time or to select a sample size based on a previous study (Omair, 2014).

Mallampati score, mouth opening, thyromental distance, ability to prognath, neck mobility and size were the independent variables. In order to collect information on the socio-demographic characteristics of the participants, a data collection sheet was designed and developed in by the principal researchers with the intention to cover all possible factors associated with difficulty in intubation (Prakash et al., 2013, Garg and Dua, 2015, Wilson and Benumof, 1998). All patients above 18 years old, ASA physical status I, II or III, both gender who required general anesthesia and orotracheal intubation were included in the study. 
However, Patients with facial abnormalities, both congenital and traumatic in whom airway assessment was not possible, patients undergoing emergency surgery, with a full stomach, tracheostomized, and those not receiving neuromuscular blocker were excluded from the study. Initial data was entered into an excel datasheet and then exported to IBM SPSS version 22 for windows for analysis. Simple bi-variable analysis was used to determine factors which are associated with difficult intubation. A $p$ value of $\otimes 0.05$ was set as significance level at $95 \%$ confidence interval. The results were presented as crude odds ratios $\left(\mathrm{OR}_{\mathrm{C}}\right)$ with $95 \%$ confidence intervals $(\mathrm{Cl})$. In order to find out indicators which made significant independent contributions to the preoperative predictors for IDS, factors which had a p-value of $\leq 0.25$ were included in multivariate logistic regression analysis, as suggested by Bendel \& Afifi. Odds ratios obtained using logistic regression analyses are presented as adjusted odds ratios (AOR) (Bendel and Afifi, 1977).

\section{Results}

From a total of 341 patients, $193(56.60 \%)$ were males and 148 (43.40\%) females. The age of the subjects ranged from 18 years to 65 years with mean age of $36.98 \pm 15.048$ years. Among the study population, $69.6 \%$ of them were from ASA Class I, $26.4 \%$ from ASA Class II, and remaining $3.8 \%$ were from ASA Class III. More than half $54.5 \%$ of the study population were from Tajik tribe, $22.3 \%$ were Pashtoons, $19.4 \%$ were Hazaras and $3.8 \%$ were Uzbeks.

The overall prevalence of difficult intubation was $26.7 \%$, whereas, $83(24.3 \%)$ had slightly difficult intubation (IDS = 5), seven ( $2.1 \%$ ) had moderate to major difficult intubation (IDS > 5), and only one patient $(0.3 \%)$ detected as failed intubation (IDS > 7).

Table 3 shows the socio-demographic characteristics of the subjects which had significant association with difficult intubation. As the table 3 shows, female participants had more risk of difficult intubation compared to male participants, with odds ratio of 1.7 and its corresponding $95 \%$ confidence interval (1.0 2.7). Patients with more than 40 years of age had increased risk of difficult intubation, as compare to those lower than 40 years old, with odds ratio of 11.1 and its correspondent $95 \%$ confidence interval (1.02.7). Hazara tribe had more risk of difficult intubation as compared to other tribes, with odds ratio of 1.9 and its corresponding $95 \%$ confidence interval $(1.1$ - 3.4). Furthermore, patients with systemic diseases (ASA II and ASA III) had increased risk for difficult intubation, as compared to those not suffering from systemic diseases with odds ratio of 4.0 and its corresponding $95 \%$ confidence interval (2.4-6.6). In the binary logistic regression analysis, age group of patients equal or more than 40 years category in sociodemographic retained its protective effect against difficult intubation.

Table 4 shows significant predictive factors associated with difficult intubation. As the analysis indicates, patients whose in Mallampati classes III and IV had higher risk of difficult intubation compared to those were in Mallampati classes I and II, with an odds ratio of 9.2 and its correspondent $95 \%$ confidence interval (3.7-22.7).Patients whose mouth opening was less or equal to $4 \mathrm{~cm}$ had higher risk of difficult intubation as compared to those with mouth opening of more than $4 \mathrm{~cm}$, with an odds ratio of 10.0 and 
its correspondent $95 \%$ confidence interval (3.8-26.1). Patients who had thyromental distance less or equal to $6 \mathrm{~cm}$ getting more difficult intubation than those who had thyromental distance more than $6 \mathrm{~cm}$, with an odds ratio of 4.0 and its correspondent $95 \%$ confidence interval (1.7-9.1). People who had no overbite, good extension, normal bite and easy to reverse their jaw had lower risk of difficult intubation as compared to those who had overbite and poor extension of their teeth, with odds ratio of 12.1 and its correspondent 95\% confidence interval (5.2-28.0). Moreover, Patients who had limited neck mobility predisposed to difficult intubation than those who did not have any reduction in neck mobility and size, with odds ratio of 8.0 and its correspondent $95 \%$ confidence interval (3.2-20.0). The multiple logistic regression analysis of predictive factors determined that ability to prognath and mouth opening as independent predictors for difficult intubation with $p$-value $=.004$ and .036 respectively at $76.5 \%$ Hosmer and Lemshow test with adjusted odds ratio be composed of 5.38 and 5.43 respectively at $95 \%$ confidence interval.

\section{Discussion}

Unanticipated difficult intubation places patients at increased risk of complications (Adnet et al., 1997). There may be soft tissue injury, trauma and subsequent airway edema, unnecessary surgical airway, inability to maintain tissue oxygenation, brain injury, cardiorespiratory arrest, and even death (Andrade et al., 2018). The role of anesthetist assistant is considered very important in influencing the outcome of an airway crisis. All decisions about alternative options in case of difficult intubation should be made with the anesthetic assistant before inducing anesthesia. More emphasis is needed on assessment, preparation, positioning, pre oxygenation, maintenance of oxygen and decreasing trauma from airway interventions (Frerk et al., 2015).

The overall prevalence of difficult intubation was found $26.7 \%$, while $24.3 \%$ had slight difficulty (IDS = 5), $2.3 \%$ moderate to major difficulty (IDS $>5$ ) in intubation, which were in line with the study conducted by Garg \& Dua in overall prevalence of difficult intubation and lower than what were reported by Smita et al., Schmitt et al. and Adnet et al., they reported slight intubation difficulty in $48.5 \%, 37 \%$ and $37.3 \%$, also moderate to major difficulty in $4.5 \%, 8 \%$ and $7.7 \%$ of patients(Garg and Dua, 2015, Prakash et al., 2013, Schmitt et al., 2002, Adnet et al., 1997). This may be because of the effect of physical characteristics of the study population, sample size and cut off point values.

Chi-square analysis found that increasing age, systemic disease, Hazara tribe and female gender were associated with difficult in intubation in our study. This probably explains the differences in the anatomical indices that are commonly used to predict difficult intubation. Likewise, according to Smita, et al., increasing age, anthropometric differences, male sex, snoring and systemic disease (Diabetes and hypertension) have an association with difficult intubation. Maryam Motamidi et al., had also reported that with an increase of age the probability of difficult intubation rises. Furthermore, a significant correlation exists between upper lip biting and Mallampati score with all anthropometric factors of the body evaluated in this study, which were close to our study (Motamedi et al., 2017). In contrast, Savva et 
al., has not reported any significant difference in age, gender, systemic disease and anthropometric factors in their study(Savva, 1994).

With regard to predictors of difficult intubations among the study population, Chi-square analysis revealed that Mallampati classes, mouth opening, thyromental distance, ability to prognath and neck mobility and size had higher risks of difficult intubation. Garg \& Dua have reported similarly (Garg and Dua, 2015). Besides, Brodsky et al. have assessed with a number of airway assessment methods including Mallampati, neck circumference, mouth opening and thyromental distance (Brodsky et al., 2002). Class III upper lip bite test (similar to AP in our cases), IID $<4.5 \mathrm{~cm}$ (similar to MO in our cases), TMD $<6.5 \mathrm{~cm}$, and SMD $<13 \mathrm{~cm}$ were defined as predictors of difficult intubation in the study conducted by Khan ZH et al (Khan et al., 2009). Sternomental distance (SMD) is an indicator of head and neck mobility(Al Ramadhani et al., 1996). . Furthermore, Sileshi Abiy Workeneh et al., indicates that mouth opening and Mallampati classes III and IV are the most sensitive assessments for predicting difficult intubation (Workeneh et al., 2017).

Multiple logistic regression analysis of predictive factors determined that increasing age, ability to prognath and mouth opening were independent predictors for difficult intubation. In contrast, Garg \& Dua concluded that Mallampati classes III and IV and ability to prognath were significant of the variables studied. Keyvan K. et al., reported that, mouth opening, chin protrusion (similar to AP in our study), and atlanto-occipital extension (similar to NM in our case) were highly significant for predicting difficult intubation (Karkouti et al., 2000). Smita, et al., identified on multivariate analysis, Mallampati classes III and IV, range of neck movement $\angle 80^{\circ}$, IID $\leq 3.5 \mathrm{~cm}$ and snoring were independently related to difficult intubation (Prakash et al., 2013).

\section{Conclusion}

Analysis of socio-demographic characteristics revealed that Hazara tribe, female patients, increasing age and systemic disease found to have significant associations with difficult intubation. We recognized that, Mallampati classes, mouth opening, thyromental distance, ability to prognath and neck mobility and size were associated with difficult intubation Multiple logistic regression analysis determined that increased age, ability to prognath and mouth opening were independent predictors for difficult intubation.

\section{Recommendations}

The authors would like to suggest the following recommendations:

1. In spite of various airway assessment tests no single test is $100 \%$ accurate. Therefore, it is advisable to use a combination of different tests. We would like to recommend anesthesia professionals to use the combination of routine preoperative tests to predict difficult intubation.

2. Anesthesia professionals should develop guideline for preoperative airway assessment to decrease prevalence of difficult 
3. Further multicenter study should be conducted in this particular topic to develop a national guideline for preoperative airway assessments.

\section{Limitations Of The Study}

The findings of this study are representative of the patients admitted to surgical wards of Aliabad Teaching Hospital. A larger sample size with widespread predictors would provide a broader idea of the topic.

\section{Declarations}

The authors declare that they have no competing interests.

MSO and AA designed the study interpreted the patient data. SAH and FN, JS, SHM contributed to the writing. All authors read and approved the final manuscript."

\section{References}

1. ADNET, F., BORRON, S. W., RACINE, S. X., CLEMESSY, J.-L., FOURNIER, J.-L., PLAISANCE, P. \& LAPANDRY, C. 1997. The intubation difficulty scale (IDS) proposal and evaluation of a new score characterizing the complexity of endotracheal intubation. Anesthesiology: The Journal of the American Society of Anesthesiologists, 87, 1290-1297.

2. AL RAMADHANI, S., MOHAMED, L., ROCKE, D., GOUWS, E. \& RAMADHANI, S. 1996. Sternomental distance as the sole predictor of difficult laryngoscopy in obstetric anaesthesia. British journal of anaesthesia, 77, 312-316.

3. ANDRADE, R. G. A. D. C., LIMA, B. L. S., LOPES, D. K. D. O., COUCEIRO FILHO, R. O., LIMA, L. C. \& COUCEIRO, T. C. D. M. 2018. Difficult laryngoscopy and tracheal intubation: observational study. Revista Brasileira de Anestesiologia, 68, 168-173.

4. BENDEL, R. B. \& AFIFI, A. A. 1977. Comparison of stopping rules in forward "stepwise" regression. Journal of the American Statistical association, 72, 46-53.

5. BRODSKY, J. B., LEMMENS, H. J., BROCK-UTNE, J. G., VIERRA, M. \& SAIDMAN, L. J. 2002. Morbid obesity and tracheal intubation. Anesthesia \& Analgesia, 94, 732-736.

6. COMBES, X., LE ROUX, B., SUEN, P., DUMERAT, M., MOTAMED, C., SAUVAT, S., DUVALDESTIN, P. \& DHONNEUR, G. 2004. Unanticipated Difficult Airway in Anesthetized PatientsProspective Validation of a Management Algorithm. Anesthesiology: The Journal of the American Society of Anesthesiologists, 100, 1146-1150.

7. FINUCANE, B. T., SANTORA, A. H. \& TSUI, B. C.-H. 2003. Principles of airway management, Springer.

8. FRERK, C., MITCHELL, V. S., MCNARRY, A. F., MENDONCA, C., BHAGRATH, R., PATEL, A. A., O'SULLIVAN, E. P., WOODALL, N. M. \& AHMAD, I. 2015. Difficult Airway Society 2015 guidelines for 
management of unanticipated difficult intubation in adults. BJA: British Journal of Anaesthesia, 115, 827-848.

9. GARG, R. \& DUA, C. 2015. Identification of ideal preoperative predictors for difficult intubation. Karnataka Anaesthesia Journal, 1, 174.

10. KARKOUTI, K., ROSE, D. K., WIGGLESWORTH, D. \& COHEN, M. M. 2000. Predicting difficult intubation: a multivariable analysis. Canadian Journal of Anesthesia, 47, 730.

11. KHAN, Z. H., MOHAMMADI, M., RASOULI, M. R., FARROKHNIA, F. \& KHAN, R. H. 2009. The diagnostic value of the upper lip bite test combined with sternomental distance, thyromental distance, and interincisor distance for prediction of easy laryngoscopy and intubation: a prospective study. Anesthesia \& Analgesia, 109, 822-824.

12. MOTAMEDI, M., SOLTANI, M., AMIRI, M., MEMARY, E. \& BARATLOO, A. 2017. Evaluating the Correlation between Intratracheal Intubation Difficulty Scoring Systems and Anthropometric Factors of Individuals' Body; an Epidemiologic Study. Iranian Journal of Emergency Medicine, 4, 68-73.

13. MOUSTAFA, M. A., EL-METAINY, S., MAHAR, K. \& MAHMOUD ABDEL-MAGIED, E. 2017. Defining difficult laryngoscopy findings by using multiple parameters: A machine learning approach. Egyptian Journal of Anaesthesia, 33, 153-158.

14. OMAIR, A. 2014. Sample size estimation and sampling techniques for selecting a representative sample. Journal of health specialties, 2, 142.

15. PRAKASH, S., KUMAR, A., BHANDARI, S., MULLICK, P., SINGH, R. \& GOGIA, A. R. 2013. Difficult laryngoscopy and intubation in the Indian population: An assessment of anatomical and clinical risk factors. Indian journal of anaesthesia, 57, 569.

16. SAVVA, D. 1994. Prediction of difficult tracheal intubation. British Journal of Anaesthesia, 73, 149153.

17. SCHMITT, H. J., KIRMSE, M. \& RADESPIEL-TROGER, M. 2002. Ratio of patient's height to thyromental distance improves prediction of difficult laryngoscopy. Anaesthesia and intensive care, 30, 763-765.

18. WILSON, W. C. \& BENUMOF, J. L. 1998. Pathophysiology, evaluation, and treatment of the difficult airway. Anesthesiology clinics of north America, 16, 29-75.

19. WORKENEH, S. A., GEBREGZI, A. H. \& DENU, Z. A. 2017. Magnitude and predisposing factors of difficult airway during induction of general anaesthesia. Anesthesiology research and practice, 2017.

\section{Tables}

Table 1.Socio-demographic characteristics of the subjects $(n=341)$ 


\begin{tabular}{|lll|}
\hline Characteristics & Classification & $\mathbf{n}(\%)$ \\
\hline Gender & Female & $148(43.40)$ \\
\cline { 2 - 3 } & Male & $193(56.59)$ \\
\hline Tribe & $<40$ & $192(56.30)$ \\
\cline { 2 - 4 } & $=>40$ & $149(43.69)$ \\
\hline ASA physical status & Tajiks & $186(54.5)$ \\
\hline Pashtoons & $76(22.3)$ \\
\hline Hazaras & $66(19.4)$ \\
\hline Uzbeks & $13(3.8)$ \\
\hline Systemic disease patients & $103(30.20)$ \\
\hline ASA Class I patients & $238(69.79)$ \\
\hline
\end{tabular}

Table 2. Preoperative airway assessments and their distribution among surgical patients in in Aliabad Teaching Hospital $(n=341)$. 


\begin{tabular}{|c|c|c|c|}
\hline Preoperative assessments & Classification & Frequency & Percent \\
\hline \multirow{4}{*}{ Mallampati classes } & Class IV & 2 & 0.6 \\
\hline & Class III & 24 & 7 \\
\hline & Class II & 101 & 29.6 \\
\hline & Class I & 214 & 62.8 \\
\hline \multirow[t]{2}{*}{ Mouth opening } & $=<4 \mathrm{~cm}$ & 24 & 7 \\
\hline & $>4 \mathrm{~cm}$ & 317 & 93 \\
\hline \multirow[b]{2}{*}{ Thyromental distance } & $=<6 \mathrm{~cm}$ & 25 & 7.3 \\
\hline & $>6 \mathrm{~cm}$ & 316 & 92.7 \\
\hline \multirow{3}{*}{ Ability to prognath } & Overbite, Poor extension & 34 & 10 \\
\hline & Normal bite, Easy to reverse & 23 & 6.7 \\
\hline & No overbite, Good extension & 284 & 83.3 \\
\hline \multirow{3}{*}{ Neck mobility and size category } & $<30^{\circ}$ short neck & 15 & 4.4 \\
\hline & $\geq 30^{\circ}$ short neck & 9 & 2.6 \\
\hline & $\geq 30^{\circ}$ normal neck & 317 & 93 \\
\hline
\end{tabular}

Table 3. Results of chi-square and logistic regression analysis for socio-demographic characteristics associated with difficult intubation. 


\begin{tabular}{|c|c|c|c|c|c|c|c|}
\hline \multicolumn{2}{|l|}{ Characteristics } & \multicolumn{2}{|c|}{ Difficult intubation } & \multirow{3}{*}{$\begin{array}{l}\mathrm{OR}_{\mathrm{C}} \text { * } \\
(\stackrel{95}{\mathrm{9}} \% \\
\mathrm{Cl})\end{array}$} & \multirow[t]{3}{*}{$\mathbf{P}$} & \multirow[t]{3}{*}{$\mathrm{AOR}^{\star \star}$} & \multirow[t]{3}{*}{ p } \\
\hline & & Present & Absent & & & & \\
\hline & & n (\%) & $\mathrm{n}(\%)$ & & & & \\
\hline \multirow[t]{3}{*}{ Gender } & Female & 48 & 100 & 1.7 & 0.036 & & \multirow{3}{*}{.189} \\
\hline & & & & $\begin{array}{l}(1.0- \\
2.7)\end{array}$ & & & \\
\hline & Male & $\begin{array}{l}43 \\
(22.3)\end{array}$ & $\begin{array}{l}150 \\
(77.7)\end{array}$ & 1 & & & \\
\hline \multirow[t]{3}{*}{ Age group } & $<40$ & 16 & 176 & 11.1 & 0.001 & 15.775 & \multirow{3}{*}{.000} \\
\hline & & & & $\begin{array}{l}(6.1- \\
20.4)\end{array}$ & & $\begin{array}{l}(7.04- \\
35.34)\end{array}$ & \\
\hline & $=>40$ & $\begin{array}{l}75 \\
(50.3)\end{array}$ & $\begin{array}{l}74 \\
(49.7)\end{array}$ & 1 & & 1 & \\
\hline \multirow[t]{3}{*}{ Tribe } & Hazara tribe & 25 & 41 & 1.9 & 0.022 & \multirow{3}{*}{ - } & \multirow{3}{*}{.104} \\
\hline & & & & $\begin{array}{l}(1.1- \\
3.4)\end{array}$ & & & \\
\hline & Other tribes & $\begin{array}{l}66 \\
(24.0)\end{array}$ & $\begin{array}{l}209 \\
(76.0)\end{array}$ & 1 & & & \\
\hline \multirow{3}{*}{$\begin{array}{l}\text { ASA physical } \\
\text { status }\end{array}$} & Systemic disease & 48 & $\begin{array}{l}55 \\
(534)\end{array}$ & 4.0 & 0.001 & \multirow{3}{*}{-} & \multirow{3}{*}{.862} \\
\hline & & & & $\begin{array}{l}(2.4- \\
6.6)\end{array}$ & & & \\
\hline & ASA Class I & $\begin{array}{l}43 \\
(18.1)\end{array}$ & $\begin{array}{l}195 \\
(81.9)\end{array}$ & & & & \\
\hline
\end{tabular}

Table 4. Results of Chi-square and logistic regression analysis for predictive factors significantly associated with difficult intubation. 


\begin{tabular}{|c|c|c|c|c|c|c|}
\hline \multicolumn{2}{|l|}{ Predictive Factors } & \multicolumn{2}{|c|}{ Difficult intubation } & \multirow{3}{*}{$\begin{array}{l}\mathrm{OR}_{\mathrm{C}}{ }^{*} \\
(95 \% \mathrm{Cl})\end{array}$} & \multirow[t]{3}{*}{$A O R^{\star \star}$} & \multirow[t]{3}{*}{ p } \\
\hline & & Present & Absent & & & \\
\hline & & $\mathrm{n}(\%)$ & $\mathrm{n}(\%)$ & & & \\
\hline \multirow[t]{3}{*}{ Mallampati classes } & Difficult & $19(73.1)$ & 7 (26.9) & 9.2 & & \\
\hline & & & & $(3.7-22.7)$ & - & .097 \\
\hline & Easy & $72(22.9)$ & $243(77.1)$ & & & \\
\hline \multirow[t]{3}{*}{ Mouth opening } & $=<4 \mathrm{~cm}$ & $18(75.0)$ & $6(25.0)$ & 10.0 & 5.436 & .036 \\
\hline & & & & $(3.8-26.1)$ & $(1.119-26.417)$ & \\
\hline & $>4 \mathrm{~cm}$ & $73(23.0)$ & $244(77.0)$ & & 1 & \\
\hline \multirow[t]{3}{*}{ Thyromental distance } & $=<6 \mathrm{~cm}$ & $14(56.0)$ & $11(44.0)$ & 4.0 & & \\
\hline & & & & $(1.7-9.1)$ & - & .277 \\
\hline & $>6 \mathrm{~cm}$ & $77(24.4)$ & $239(75.5)$ & & & \\
\hline \multirow[t]{3}{*}{ Ability to prognath } & Difficult & $26(76.5)$ & $8(23.5)$ & 12.1 & 5.382 & .004 \\
\hline & & & & $(5.2-28.0)$ & $(1.725-16.792)$ & \\
\hline & Easy & $65(21.2)$ & $242(78.8)$ & & 1 & \\
\hline \multirow[t]{3}{*}{ Neck mobility and size } & Difficult & $17(70.8)$ & $7(29.2)$ & 8.0 & & \\
\hline & & & & $(3.2-20.0)$ & - & .438 \\
\hline & Easy & $74(23.3)$ & $243(76.7)$ & & & \\
\hline
\end{tabular}

*Crude Odds Ratio **Adjusted Odds Ratio $\quad$ 1= Reference category

\section{Figures}




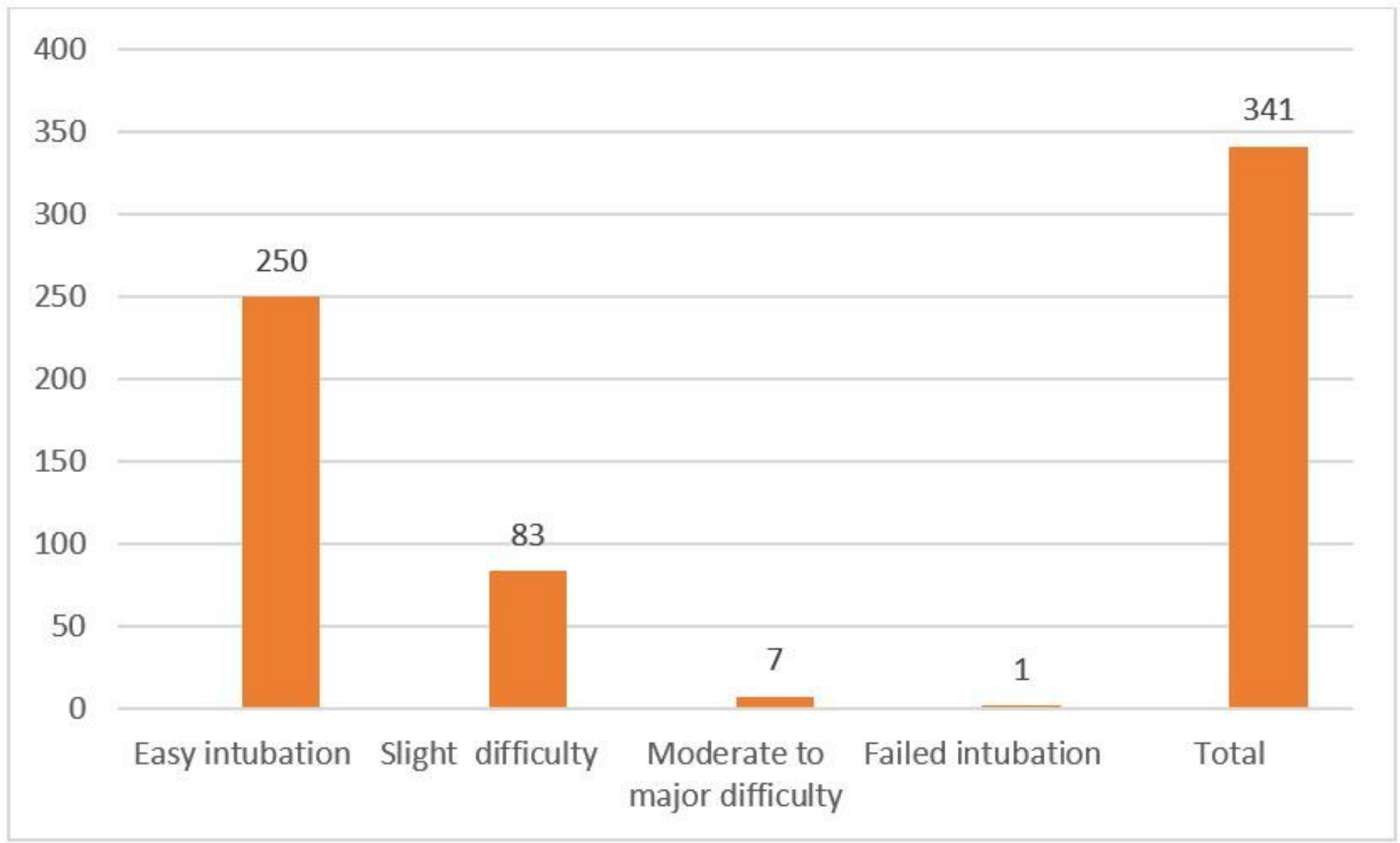

\section{Figure 1}

Intubation Difficulty Scale 